\title{
KARAKTERISTIK KERTAS BERBAHAN KERTAS BEKAS DAN LIMBAH RUMPUT LAUT Eucheuma cottonii
}

\section{PAPER CHARACTERISTIC OF USED PAPER AND SEAWEED WASTE Eucheuma cottonii}

\author{
Ignacius D. Sukaryono dan Voulda D. Loupatty \\ Balai Riset dan Standarisasi Industri Ambon \\ Jl. Kebun Cengkih, Ambon 97128 \\ e-mail : dhaniigna@yahoo.com; voulda_loupatty@yahoo.co.id
}

Received : 19/12/2018; revised : 19/12/2018; accepted : 31/12/2018

Published online : $31 / 12 / 2018$

\begin{abstract}
ABSTRAK
Kertas dibutuhkan setiap hari untuk berbagai keperluan, baik untuk perkantoran, dunia pendidikan sampai ke pengemasan.Tujuan penelitian ini adalah untuk mengetahui karakteristik kertas berbahan kertas bekas dan limbah rumput laut Eucheuma cottonii. Penelitian dilakukan dengan tahapan penyobekan kertas bekas, perendaman, penghalusan dan pengeringan. Formulasi proses pembuatannya dengan perlakuan : $\mathrm{A}=\mathrm{Limbah}$ kertas ; $\mathrm{B}=$ Limbah kertas : Limbah rumput laut $(1: 1) ; \mathrm{C}=\operatorname{Limbah}$ kertas: Tapioka $(1: 0,1) ; \mathrm{D}=\operatorname{Limbah}$ kertas : Limbah rumput laut: Tapioka $(1: 0,9: 0,1)$. Setiap perlakuan dibuat 4 kali ulangan. Produk kertas hasil daur ulang, dilakukan pengamatan secara visual terhadap sifat fisik kertas yang meliputi kehalusan permukaan kertas, warna kertas,ketebalan kertas,daya serap,daya lipat dan daya sobek, dengan pembandingnya adalah kertas HVS dan kertas buram atau kertas koran. Hasil penelitian menunjukkan bahwa produk kertas daur ulang yang dihasilkan umumnya mempunyai permukaan kertas yang kasar, berwarna putih keabuan, dapat dilipat dan dapat disobek kecuali perlakuan A mempunyai daya sobek tidak beraturan, mempunyai daya serap, gramatur dan ketebalan yang lebih tinggi sedangkan nilai densitasnya lebih rendah dibandingkan perlakuan lainnya. Formula ini dapat digunakan untuk pengembangan pembuatan rak telur.
\end{abstract}

Kata kunci: Eucheuma cottonii, kertas daur ulang, limbah kertas, limbah rumput laut

\begin{abstract}
Paper is needed every day for various purposes, both foroffices, the world of education and packaging. The purpose of this study was to determine the characteristics of used paper and seaweed waste Eucheuma cottonii. The researchare used paper tearing, soaking, smoothing and drying. Formulations are made in the manufacturing process with treatment: $A=$ Paper waste; $B=$ Paper waste : Seaweed waste (1: 1); $C=P a p e r$ waste : Tapioca (1: 0,1); $D=$ Paper waste: Tapioca : seaweed waste (1: 0.9:0,1). Each treatment was made 4 replicants. Recycled paper products are carried out visually on the physical properties of the paper which include: paper surface fineness, paper color, paper thickness, absorbency, folding power and tear power, with comparison being HVS paper and opaque paper or newspaper paper. The results showed that the recycled paper products produced generally had a rough surfaces, grayish-white color, could be folded and could be torn apart unless treatment $A$ had iiregular tear power, had a higher absorption capacity, grammage and thickness while lower density values compared to other treatments. This formula can be used for the development of egg rackmaking.
\end{abstract}

Keywords: Eucheuma cottonii, paper waste, recycled paper, seaweed waste

\section{PENDAHULUAN}

Kertas merupakan kebutuhan primer karena digunakan sehari-hari untuk berbagai keperluan perkantoran,dunia pendidikan sampai ke pengemasan. Industri kertas merupakan salah satu jenis industri terbesar di dunia dengan menghasilkan 278 juta ton kertas dan karton, dan menghabiskan 670 juta ton kayu. 1 ton kertas tulis membutuhkan 24 pohon berumur 10 tahun (Sintaria, 2012). Sahat (2015) menyebutkan bahwa 1 pohon dapat menghasilkan 15 rim kertas ukuran A4. Sedangkan untuk mendapatkan 7000 eksemplar 
koran yang dibaca setiap hari akan membutuhkan 10-17 pohon hutan..

Falrisya (2006) menyebutkan bahwa produksi 1 ton kertas dibutuhkan 3 ton kayu dan melepaskan $\mathrm{CO}_{2}$ sekitar 2,6 ton, yang sama dengan emisi buang mobil selama 6 bulan. Selanjutnya, Gembaladomba (2013) menyebutkan bahwa160 ton limbah kertas setara dengan 2.400 batang pohon yang berumur sekitar 10 tahun sehingga berpotensi untuk digunakan sebagai bahan baku. dalam waktu singkat. Menurut Chica, (2010), daur ulang adalah proses untuk menjadikan suatu bahan bekas menjadi bahan baru dengan tujuan mencegah adanya sampah yang sebenarnya dapat menjadi sesuatu yang berguna, mengurangi penggunaan bahan baku yang baru, mengurangi penggunaan energi, mengurangi polusi, kerusakan lahan, dan emisi gas rumah kaca jika dibandingkan dengan proses pembuatan barang baru. Daur ulang adalah salah satu strategi pengelolaan sampah padat yang terdiri atas kegiatan pemilahan, pengumpulan, pemrosesan, pendistribusian dan pembuatan produk/ material bekas pakai, dan komponen utama dalam manajemen sampah modern.

Umur pohon yang dapat digunakan untuk produksi kertas sekitar 10 tahun.Hal ini menjadi kelemahan daya saing industri kertas.Limbah rumput laut dapat digunakan sebagai bahan baku untuk produksi kertas. Hal ini didukung oleh wilayah laut Indonesia, menyediakan lahan budidaya rumput laut yang begitu luas dan belum dimanfaatakan secara maksimal. Di mana waktu yang dibutuhkan untuk budidaya rumput laut sampai panen bahkan sampai proses pengeringan hanya sekitar 60 hari ( 2 bulan), itu berarti dalam setahun dapat 5 kali panen. Eucheuma sp. mengandung karbohidrat 35 $40 \%$, komponen selulosa sebesar $16-20 \%$, hemiselulosa 18-22 \%, lignin 7-8 \% dan serat kasar. 2,5-5 \% (Riyanto, 2006). Beberapa penelitian yang mendukung pemanfaatan limbah rumput laut sebagai bahan baku kertas telah dilakukan oleh Sintaria (2012) tentang pengaruh konsentrasi hidrogen peroksida $\left(\mathrm{H}_{2} \mathrm{O}_{2}\right)$ dan konsentrasi tapioka terhadap sifat fisik kertas berbasis ampas rumput laut Eucheuma cottonii. Penelitian lainnya dilakukan Hardiansyah (2013) tentang kualitas kertas daur ulang dari ampas rumput laut Gracilaria sp. Dengan demikian rumput laut merupakan sumber bahan baku kertas masa depan. Sehingga tujuan penelitian ini adalah untuk mengetahui karakteristik kertas berbahan kertas bekas dan limbah rumput laut Eucheuma cottonii untuk pemanfaatan yang lebih efektif.

\section{METODE PENELITIAN}

\section{Bahan dan Alat}

Bahan yang digunakan adalah limbah kertas HVS, limbah rumput laut Eucheuma cottonii hasil produksi karaginan atau bioetanol dan tapioka.Penelitian ini menggunakan alat antara lain mikrometer, ember, blender, timbangan, pengaduk, screen, kain dan spons.

\section{Tahapan Penelitian}

Limbah kertas HVS ditimbang, disobek kecil-kecil dan direndam dalam ember besar selama 48 jam. Sobekan kertas tersebut diblender sampai menjadi bubur dibuat dengan perbandingan air : kertas (3:1. Selanjutnya dibuat perlakuan $: A=$ Limbah kertas $100 \%$; $B=$ Limbah kertas $50 \%$ dan limbah rumput laut $50 \%$ (1: 1); C = Limbah kertas 90\% dan tapioka $10 \%(1: 0,1) ; D=$ Limbah kertas $50 \%$,limbah rumput laut $40 \%$ dan tapioka $10 \%$ (1: $0,9: 0,1)$.Masing-masing perlakuan dibuat 4 kali ulangan. Tiap perlakuan dicampur merata, selanjutnya dicetak dan dikeringkan

\section{Pengamatan}

Kertas yang dihasilkan dari proses daur ulang kertas dilakukan pengamatan fisik, baik secara visual maupun dengan pengukuran parameter-parameter. Secara visual meliputi kehalusan permukaan kertas dilakukan dengan cara melihat dan meraba permukaan kertas; warna kertas dibandingkan dengan kertas HVS dan kertas koran; daya lipat dengan cara melipat kertas daur ulang dengan memperhatikan bentuk lipatannya secara mendatar maupun memanjang; daya sobek dengan cara menyobek kertas daur ulang dan memperhatikan bentuk sobekannya dan dibandingkan dengan kertas HVS dan kertas buram atau kertas koran; daya serap, mencelup kertas daur ulang ke dalam larutan berwarna selama 10 detik dan memperhatikan daya serapnya. Pengukuran beberapa parameter yang meliputigramatur kertas yang merupakan massa kertas per satuan luasnya dalam meter persegi dengan cara mengukur berat dasar kertas daur ulang dengan ukuran $10 \times 10 \mathrm{~cm}$ dibagi luas kertas. Parameter yang kedua adalah ketebalan kertas, mengukur ketebalan kertas daur ulang pada lima titik berbeda menggunakan alat micrometer dan parameter densitas $\left(\mathrm{g} / \mathrm{m}^{3}\right)$, diperoleh dari gramatur dibagi tebal kertas.

\section{HASIL DAN PEMBAHASAN}

\section{Proses pembuatan kertas daur ulang}

Perubahan berat dalam tiap tahap proses pembuatan kertas daur ulang, hasil rata-rata dari 4 kali ulangan, dapat dilihat pada Tabel 1. 
Tabel 1. Perubahan Berat Dalam Tiap Tahap Proses Pembuatan Kertas Daur Ulang

\begin{tabular}{lcccc}
\hline \multicolumn{1}{c}{ Uraian Tahapan } & \multicolumn{3}{c}{ Perubahan Berat (gram) } \\
\cline { 2 - 5 } & A & B & C & D \\
\hline Berat kertas bekas & 42,5 & 35,75 & 37 & 36,5 \\
Setelah perendaman & 108 & 86,75 & 91 & 88,25 \\
Penambahan air sebanyak 3 kali & 325 & 262,5 & 275 & 265 \\
Dibuat sesuai perlakuan dan diblender & 320 & 298 & 310 & 306 \\
Setelah pengeringan & 43,5 & 37,5 & 38,5 & 41 \\
\hline
\end{tabular}

Keterangan :

$A=$ Limbah kertas $100 \%$

$\mathrm{B}=$ Limbah kertas 50\% dan limbah rumput laut 50\% (1:1)

$\mathrm{C}=$ Limbah kertas $90 \%$ dan tapioka $10 \%(1: 0,1)$

$\mathrm{D}=$ Limbah kertas 50\%, limbah rumput laut 40\% dan tapioka 10\% (1:0,9:0,1)

Tabel 1 menunjukkan bahwa produk kertas setelah pengeringan untuk semua perlakuan mempunyai berat yang lebih tinggi dari berat bahan yang digunakan. Adanya perubahan berat yang lebih tinggi ini disebabkan karena ketebalan kertas produk akhir lebih tebal dari bahan baku (lembaran kertas bekas), sehingga diduga kadar air produk akhir lebih tinggi dari bahan baku. Selain itu peningkatan berat pada produk akhir juga disebabkan oleh adanya bahan tambahan yang digunakan dalam proses produksi kertas daur ulang, dimana daya serap dari bahan tambahan yang digunakan juga berbeda-beda.

\section{Sifat fisik kertas}

Kertas yang dihasilkan dari proses daur ulang kertas dilakukan pengamatan fisiksecara visual. Hasil pengamatan visual terhadap kehalusan permukaan kertas, warna, daya lipat dan daya sobek, dengan pembanding kertas HVS dan kertas buram atau kertas Koran, dapat dilihat pada Tabel 2.

Tabel 2 menunjukkan bahwa produk kertas daur ulang yang dihasilkan umumnya mempunyai permukaan kertas yang kasar, berwarna putih keabuan, dapat dilipat dan dapat disobek, kecuali perlakuan A (tanpa bahan tambahan) mempunyai daya lipat dan daya sobek tidak beraturan dan rapuh. Hal ini disebabkan produknya agak tebal dan tidak menggunakan bahan tambahan sebagai bahan pengisi diantara pori-porinya yang dapat berfungsi sebagai pengikat antara struktur kertas.

\section{Daya Serap}

Daya serap kertas daur ulang yang diperoleh dalam penelitian ini, dapat dilihat pada Gambar 1.

Gambar 1 menunjukkan bahwa daya serap tertinggi diperoleh dari perlakuan $A$ yaitu daur ulang kertas tanpa bahan tambahan. Sebaliknya daya serap terendah diperoleh dari perlakuan $D$ yaitu daur ulang kertas dengan bahan tambahan tapioka dan ampas rumput laut. Daya serap ditentukan oleh porositas sedangkan porositas merupakan bagian dari struktur kertas. Hasil penelitian ini menunjukkan bahwa daur ulang kertas dengan penambahan tapioka dan ampas rumput laut dapat memenuhi pori-pori atau struktur kertas sehingga mengurangi daya serap air. Daya serap biasanya berkaitan dengan penyerapan tinta serta pengeringan hasil cetak. Sifat daya serap air dipengaruhi oleh sizer dan filler. Sizer akan mengubah sifat hidrofilik selulosa menjadi hidrofobik sehingga kemampuan penyerapan airnya akan berkurang. (Rochlan, 1990).

Tabel 2. Sifat Fisik (Kehalusan, Warna, Daya Lipat dan Daya Sobek) Kertas Daur Ulang

\begin{tabular}{cllll}
\hline \multirow{2}{*}{ Perlakuan } & \multicolumn{4}{c}{ Sifat Fisik Kertas Daur Ulang } \\
\cline { 2 - 5 } & $\begin{array}{c}\text { Kehalusan } \\
\text { Permukaan }\end{array}$ & \multicolumn{1}{c}{ Warna } & \multicolumn{1}{c}{ Daya Lipat } & Daya Sobek \\
\hline A & Kasar & Putih keabuan & $\begin{array}{l}\text { Dapat dilipat, namun tidak } \\
\text { beraturan dan rapuh }\end{array}$ & $\begin{array}{l}\text { Ketika disobek, tidak } \\
\text { beraturan } \\
\text { B }\end{array}$ \\
Kasar & Kasar & Putihkeabuan & Dapat dilipat & Dapat disobek \\
D & Kasar & Putih keabuan & Dapat dilipat & Dapat disobek \\
Putihkeabuan & Dapat dilipat & Dapat disobek \\
\hline
\end{tabular}

\footnotetext{
${ }^{*}$ Pengamatan secara visual, dengan pembanding kertas HVS dan Kertas buram/kertas Koran
} 


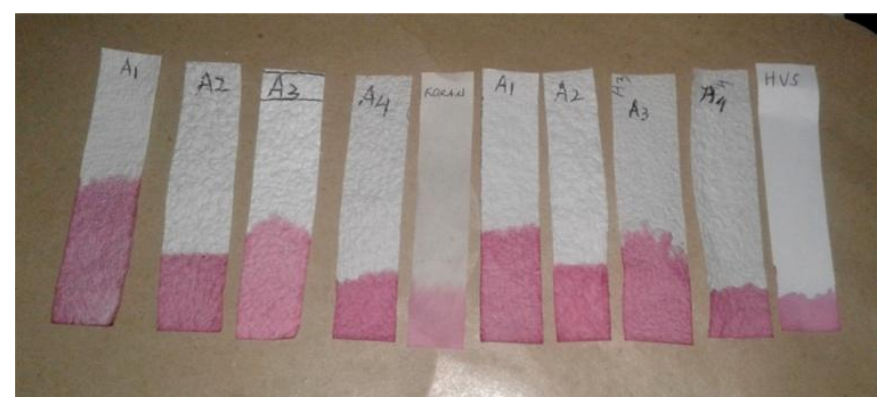

Gambar 1. Daya Serap Kertas Daur Ulang

keterangan :

$\mathrm{A} 1=\mathrm{A}=$ Limbah kertas $100 \%$

$A 2=B=$ Limbah kertas $50 \%$ dan limbah rumput laut $50 \%(1: 1)$

A3 $=C=$ Limbah kertas $90 \%$ dan tapioka $10 \%(1: 0,1)$

$\mathrm{A} 4=\mathrm{D}=$ Limbah kertas 50\%, limbah rumput laut 40\% dan tapioka $10 \%(1: 0,9: 0,1)$

\section{Pengamatan menggunakan alat ukur}

Pengamatan menggunakan alat ukur meliputi berat dasar (gramatur), ketebalan dan densitas kertas daur ulang hasil penelitian ini dapat dilihat pada Tabel 3 .

Tabel 3 menunjukkan bahwa nilai gramatur sejalan dengan ketebalan. Di mana nilai tertinggi diperoleh dari perlakuan A (tanpa bahan tambahan), sedangkan nilai terendahdiperoleh dari perlakuan B (bahan tambahan rumput laut). Sebaliknya nilai densitas tertinggi diperoleh dari perlakuan $\mathrm{C}$ (bahan tambahan tapioka) dan nilai terendah diperoleh dari perlauan A (tanpa bahan tambahan). Gramatur merupakan nilai yang menunjukkan bobot bahan per satuan luas bahan. Dimana makin tinggi nilai berat kertas makin tinggi pula berat nilai gramaturnya. Nilai gramatur ini juga ada hubungannya dengan ketebalan. Sedangkan nilai densitas kertas dipengaruhi oleh nilai gramatur dan nilai ketebalan. Densitas suatu kemasan memiliki hubungan berbanding terbalik dengan permeabilitasnya. Semakin rendah suatu permeabilitas maka kemampuan kemasan untu menahan udara masuk ke dalam kemasan semakin tinggi. Menurut Casey (1981), Gramatur kertas mempengaruhi semua sifatsifat kertas. Densitas kertas diperoleh dengan membagi gramatur contoh bahan dengan tebal bahan. Nilai densitas kertas dipengaruhi oleh nilai gramatur dan tebal kertas. Secara teknis rapat massa mempunyai hubungan erat dengan daya ikatan antar serat dan derajat fibrilisasi serat pulp yang nantinya berpengaruh pada saat pencetakan (opasitas cetak) . Selanjutnya menurut Joedodibroto (1982), adanya keragaman dalam gramatur mengindikasikan pada fluktuasi pemakaian bahan baku kertas per satuan luas. Semakin kecil gramatur maka penggunaan bahan baku semakin sedikit, konsumsi energi untuk pengolahan kertas lebih rendah, mengurangi polusi pabrik, biaya penanganan bahan dan produk rendah, efisiensi ruang penyimpanan, memperkecil gulungan atau potongan yang nantinya akan meningkatkan efisiensi dan efektifitas proses pembuatan kertas (karton) secara keseluruhan, Formulasi kertas daur ulang dapat diaplikasikan pada pabrik pembuatan rak telur. Dalam Kurniasih (2013), menyebutkan kualitas rak telur yang baik dihasilkan dari kertas daur ulang yang diberi bahan tambahan CMC (Carboxy Metil Cellulosa) dan tepung tapioca. Untuk pengembangan formulasi dan dapat menekan biaya produksi, maka sebaiknya penggunaan CMC digantikan dengan ampas rumput laut.

Tabel 3 . Gramatur, Ketebalan dan Densitas Kertas Daur Ulang

\begin{tabular}{ccccc}
\hline Perlakuan & Berat $\mathbf{( g )}$ & Gramatur $\left(\mathbf{g} / \mathbf{m}^{\mathbf{2}}\right)$ & Tebal $\mathbf{( m )}$ & Densitas $\mathbf{( g / \mathbf { m } ^ { 3 } )}$ \\
\hline A & 3,00 & 300 & $87.10^{-5}$ & $3,45.10^{5}$ \\
B & 1,20 & 120 & $21.10^{-5}$ & $5,71.10^{5}$ \\
C & 2,20 & 220 & $35.10^{-5}$ & $6,28.10^{5}$ \\
D & 2,52 & 252 & $47.10^{-5}$ & $5,36.10^{5}$ \\
\hline
\end{tabular}

$B=$ Limbah kertas $50 \%$ dan limbah rumput laut $50 \%(1: 1)$

$\mathrm{C}=$ Limbah kertas $90 \%$ dan tapioka $10 \%(1: 0,1)$

$\mathrm{D}=$ Limbah kertas 50\%, limbah rumput laut 40\% dan tapioka 10\% $(1: 0,9: 0,1)$ 


\section{KESIMPULAN}

Berdasarkan hasil penelitian dapat disimpulkan bahwatahapan produksi kertas daur ulang berbahan baku limbah kertas dengan penambahan limbah rumput laut dan tapioka adalah : perendaman kertas bekas selama 2 hari, hasil rendaman diblender dengan penambahan air sebanyak 3 kali selanjutnya diberikan bahan tambahan sesuai perlakuan, dicetak dan dikeringkan. Sifat fisik kertas daur ulang berbahan baku limbah kertas (A) adalah mempunyai permukaan kertas yang kasar, berwarna putih keabuan, mempunyai daya lipat dan daya sobek tidak beraturan dan rapuh, mempunyai daya serap, gramatur maupun ketebalan yang lebih tinggi dari lainnya, sedangkan nilai densitasnya lebih rendah dibandingkan perlakuan lainnya.Sifat fisik kertas daur ulang berbahan baku limbah kertas dengan penambahan : ampas rumput laut (B), tapioka (C) dan campuran ampas rumput laut dan tapioka (D) adalah mempunyai permukaan kertas yang kasar, berwarna putih keabuan, dapat dilipat dan dapat disobek, mempunyai daya serap lebih rendah dari perlakuan $A$, nilai gramatur terendah $\mathrm{B}$ dan densitas tertinggi $\mathrm{C}$. Hasil kertas daur ulang ini dapat dimodifikasi sesuai kebutuhan untuk keperluan pengemasan, khususnya dalam pembuatan rak telur.

\section{DAFTAR PUSTAKA}

Casey, J.P. 1981. Pulp and Paper, vol.II Second Ed. International Publisher Inc. NewYork.

Chica. 2010. Membuat Kertas Daur Ulang, http://chicamayonnaise.blogspot.co.id/?m=1 Tanggal akses 6 Agustus 2016

Falrisya, D. 2010. Artikel "Efek Produksi Kertas Terhadap Lingkungan, Program Magister Desain, Institut Teknologi Bandung. http://o2indonesia.wordpress.com Tanggal akses 6 Agustus 2016

Gembaladomba, 2013 . Proses Pembuatan Kertas (Save earth). proses pembuatan kertas kaskus. The Largest Indonesia Community. Diakses 24 Februari 2016.

Hardiansyah, Y. 2013. Kualitas Kertas Daur Ulang Dari Ampas Rumput Laut Jenis Gracilaria sp. Skripsi. Universitas Gajah Mada . Yogyakarta.

Joedodibroto, H. 1982. Plan Plantation Residues as an Alternative Sourece of Cellulosaic

Kurniasih, P. 2013. Kelayakan Usaha Pembuatan Produk Kemesan Telur dari Kertas Limbah di Sumatera Barat. Jurnal Penelitian Sosial dan Ekonomi Kehutanan 10(3): 157-172.
Riyanto, B. 2006. Berkadar serat tinggi substitusi tepung ampas rumput laut dari pengolahan agar-agar kertas. Buletin Teknonogi Hasil Perikanan 9: 47-57.

Rochlan, F. 1990. Kemasan Karton dalam Industri pangan. Di dalam : S.Fardiaz dan D.Fardiaz (ed), Risalah Seminar Pengemasan dan Transportasi dalam Menunjang Pengembangan Industri, Distribusi dalam Negeri dan Ekspor Pangan. Jakarta.

Sahat, S. 2015. Pengaruh Penggunaan Kertas Terhadap Kondisi Hutan Indonesia Tahun 2015_sahat sijabat htpn.htm .Diakses 26 Februari 2016.

Sintaria, D, 2012. Pengaruh Konsentrasi Hidrogen Peroksida $\left(\mathrm{H}_{2} \mathrm{O}_{2}\right)$ Dan Konsentrasi Tapioka Terhadap Sifat Fisik Kertas Berbasis Ampas Rumput Laut Eucheuma cottonii .Skripsi. Fakultas Pertanian. Universitas Lampung . Bandar Lampung. 